\title{
Review of the current status of smoking cessation in the USA: assumptions and realities
}

\author{
John M Pinney
}

This is going to be a whirlwind tour through the treatment system, describing the realities for people who are trying to quit smoking in today's treatment environment. First, I want to explore the basic assumptions that underlie, and in some cases inappropriately influence, how we look at the treatment of tobacco addiction. Next, I want to provide some of the characteristics of the system, recognising that there is really no comprehensive description of tobacco treatment available to us. And finally, I want to look at the factors that I think affect the system and will affect it in the future.

There are three basic assumptions. First, we often say "most smokers quit on their own", and that has some very significant implications. It permeates the thinking of many of the health care providers who are supposed to be addressing this problem. Second, we have communicated the idea that if you want help to quit smoking, it is available to you. And third, we have said, with some evidence, that tobacco control policies create incentives for cessation, and we also have said that the economic justification for smoking cessation is irresistible - the numbers are overwhelming.

Let me examine the assumptions briefly. The first assumption is that most smokers quit on their own. ${ }^{1}$ I do not think we know whether that is a preference or whether that is by default. We do not often ask smokers about why they choose to do what they do. We also know that they often do not recall what it was they finally did to quit smoking, or they may recall what they finally did, but not what they did the first two or three times they tried and failed. The idea that they quit on their own suggests, I think, that we know very little about what that truly means in a treatment context.

The success of quitting smoking on one's own is not very high. Our calculations are usually based on the numbers of people who continue to abstain after the first 24 hours. Since there are millions of people who do not make it past 24 hours, we need to ask ourselves "What, then, is the true efficacy of quitting on your own?". I suggest it is somewhere between $4 \%$ and $5 \%$ at best. ${ }^{2}$ What are the public health implications of this? As Dr Orleans has shown, we have built a public health model which implies that if we do certain things we will drive people either to quit on their own or into treatment. The next question is "If they seek treatment, how available is it; how accessible is treatment?" I shall examine that in more detail.

The next assumption is that tobacco control policies create incentives for cessation. I have tried to characterise this with two thoughts: (1) "If you ban it, they will quit." From Dr Orleans' COMMIT data it seems that this is not necessarily the case. Certainly the results are mixed - and in the workplace, where we have probably had our most extensive impact in eliminating smoking - we may in many cases only have changed people's smoking patterns rather than inducing them to quit. ${ }^{3}$ (2) The second thought is "If you tax it high enough, they will quit". I suspect that this is probably one of our best hopes, ${ }^{4}$ but as we all know it is very hard to raise taxes.

The final assumption is that the economic justification for smoking cessation is irresistible. I quote from the late Rufus Miles, a great public servant, who said, "Where you stand depends on where you sit". Those of us who believe that the economic justification is overwhelming and irresistible do not run managed care plans. Those who do have found ways to resist the logic of this and continue to resist it.

I shall now examine the availability of products and services, beginning with group programmes. I think group programmes are what the US Food and Drug Administration (FDA) meant - although they said two years ago at our last conference they were not absolutely certain - when they coined the term "comprehensive behavioural smoking cessation programme." Group programme demand is hard to measure. All the reports we have are self reports from vendors, but it appears that demand is either flat or declining. ${ }^{5}$ We conducted a brief informal survey of group programmes in 10 cities in the United States and found that in four of them no group programmes were being offered by a major voluntary health agency because of a lack of demand.

Whether or not these programmes are "smoker-friendly," that is, whether or not they would attract smokers into treatment, is questionable. There are several anecdotes that suggest that the location, scheduling, duration, and format of group programmes are not necessarily smoker-friendly.

Table 1 presents self reported data from the three primary commercial smoking cessation group vendors. ${ }^{5}$ It suggests there was a substantial increase in sales between 1988 and 
Table 1 Cessation programme unit sales by commercial group vendors, 1988-1993

\begin{tabular}{lrrrr}
\hline Programme & 1988 & 1992 & 1993 & $\begin{array}{c}\% \text { change } \\
\text { 1988-93 }\end{array}$ \\
\hline SmokEnders & 15000 & 10000 & 10000 & -33 \\
Smoke Stoppers & 30000 & 56000 & 30000 & 0 \\
SmokeLess & 28000 & 45000 & 68000 & +143 \\
Total & 73000 & 111000 & 108000 & +48 \\
\hline
\end{tabular}

Source: Marketdata, 1989; Marketdata/CHPG 1994.

Table 2 Estimated sales of non-prescription smoking cessation programmes and products, 1993

\begin{tabular}{lr}
\hline Programme & Volume (units) \\
\hline Acupuncture & 85000 \\
Hypnosis & 350000 \\
American Cancer Society & 150000 \\
American Heart Association & 19000 \\
7th Day Adventists & 85000 \\
Addiction Management System & 5000 \\
SmokEnders & 10000 \\
Smoke Stoppers (group) & 30000 \\
Smoke Stoppers (self help) & 10000 \\
SmokeLess (group) & 65000 \\
SmokeLess (self help) & 50000 \\
Nonaffiliated Hospitals & 175000 \\
American Lung Association (group) & 30000 \\
American Lung Association (video) & 1500 \\
American Lung Association (self help) & 50000 \\
American Medical Association/GNC & 5000 \\
Total & 1120500 \\
\hline
\end{tabular}

Source: Marketdata, 1989; Marketdata/CHPG 1994

Table 3 Survey data on physician advice and assistance

\begin{tabular}{lcc}
\hline Question & Yes/No (\%) & Source \\
\hline $\begin{array}{l}\text { Ever been advised to quit } \\
\begin{array}{l}\text { Doctor explained and } \\
\text { counselled how to quit }\end{array}\end{array}$ & $61 / 39$ & Gallup 1993 \\
$\begin{array}{l}\text { Been advised to quit in } \\
\text { last 12 months }\end{array}$ & $51 / 49$ & Gallup 1993 \\
\hline
\end{tabular}

* National Health Interview Survey.

1993 - overall, about a $48 \%$ increase. However, it is hard to know how much of that increase was driven by the short term effects of the introduction of the transdermal nicotine patch, as opposed to any major shift in consumer demand, and we do not have data later than 1993 to present. My informal survey, as I said, would suggest that demand may be flat or declining.

Most of these programmes, it is important to note, are presented by hospitals affiliated with these vendors, and much of the activity in 1992 and 1993 may be attributable to the increase in bans in smoking or increase in smoking restrictions in the workplace. Again we have no recent data, but I believe that this trend will now have levelled off because many workplaces have become smoke-free, and there is little interest in smoking cessation group programmes on the part of the employees.

Table 2 shows an overall estimate of the smoking cessation programmes and products, other than prescription products, in 1993 (Corporate Health Policies Group, unpublished data, 1994). It runs from acupuncture down to the American Medical Association/ General Nutrition Centers programme, which was launched about 18 months ago. Some of these data are self reported, some are imputed from other sources. It is as close as I have seen to an estimate of the total use of smoking cessation products and programmes in the United States. These are 1993 numbers, and the total is about 1.12 million units, products, or group programme participants. It is a little over $6 \%$ of the 16 or 17 million people who make an attempt to stop smoking lasting over 24 hours.

Physicians are clearly an important part of the treatment system. There are fewer individual practitioners in the system today, although much of what we say about physicians and cessation seems still to be focused on doctors as though they practise the way they practised 10 years ago. More group practices are being bought up by managed care and placed under the pressures that managed care exerts on physicians to deliver inexpensive health care. Managed care is growing substantially, and it places a reliance on guidelines, which physicians tend to ignore as some studies show. ${ }^{5}$ Finally, we have a guide for the behaviour of physicians: a strong recommendation from the US Preventive Services Task Force that behavioural counselling should be a requirement for all smokers. ${ }^{6}$ Clearly, physicians should deliver counselling, but we have evidence that they are not paying attention to the guidelines. ${ }^{5}$

Table 3 presents three different measures of counselling activity. First, a Gallup survey done in 1993 for SmithKline Beecham Consumer Healthcare, asked "Have you ever been advised to quit by your physician?" Sixty one percent answered in the affirmative. In response to the question "Did the doctor explain and counsel you how to quit?", the Gallup poll found that $51 \%$ of those who had been advised were actually counselled how to quit. ${ }^{7}$ The National Health Information Survey (NHIS) data show that $37 \%$ of smokers said they had been advised to quit in the last 12 months. ${ }^{8} \mathrm{I}$ submit that the results of physicians following guidelines are not particularly encouraging so far.

Hospitals are another major element in the system. Hospitals have varied objectives in today's health care system, particularly when it comes to treating "behavioural problems" like smoking. They treat them for community relations purposes, perhaps their top priority. They also do it as a loss leader, to bring people into the hospital to deliver other services. Some do it for profit, although I heard an anecdote about a booming health promotion programme in a hospital that was purchased by a chain. The chain said "We are not in the business of doing this even though you are 
making a profit," and cancelled the programme. Hospitals also offer treatment programmes as a contract service for employers in the community. ${ }^{5}$

We found in a survey of about 20 hospitals that several actually do provide smoking cessation treatment under contract to employers and to some managed care programmes, but the trends are unclear. ${ }^{5}$ It appears the demand may be flagging for group programmes, which are primarily what hospitals supply. Estimates of hospital cessation services not affiliated to a national vendor show that, if anything, there may be nil to modest growth in cessation activity; patient volume for these services has grown from 179600 in 1988 to 188600 in 1992 , a $5 \%$ increase. ${ }^{5}$ However, these data are three years old and health systems integration is underway, which means that hospitals and doctors are teaming up to fight back against managed care, and they will be subject to many of the same pressures as managed care, meaning a reduction of costs. There are other indications that hospitals are not encouraging the demand for cessation services. Our survey of 20 hospitals in 1994 found that cessation fell into the "not hot" category of health promotion/ disease prevention services.

The next, and probably the most important, element of the system is managed care. Managed care has always maintained that prevention is its middle name. When the federal government made it possible for health maintenance organisations to become federally chartered and get federal start-up money, the Congressional hearings were replete with justifications based on prevention. Second, while the economic justification is irresistible, it is also inescapable; sooner or later, a large group of people whose care is being managed by a single entity is going to incur smoking-related diseases.

Part of the problem with managed care and with the resistance to the economic imperative of smoking is that managed care believes short term competitive forces are far more powerful than long term health and economic considerations. However, I believe that the demographics and the customer demand factors in managed care are going to change that situation to some extent. Clearly, if we are going to be managing the care of the entire population, we can no longer expect managed care to have the benefit of only healthy young people who do not smoke or do other things which cost money.

The Group Health Association of American (GHAA) reported that in 1992 , only $3 \%$ of all enrollees in health maintenance organisations were not covered for routine physical examinations, but $33 \%$ of all people enrolled in them were not covered for smoking cessation. ${ }^{9}$

I should like to present some data which were collected in 1993 in an extensive survey of health maintenance organisations. ${ }^{10}$ This survey was sponsored by Ciba-Geigy - which has graciously agreed to let the data be released and was conducted by the Corporate Health Policies Group (CHPG). The data are two years old, but they are from an extensive sample - not a generalisable one per se, but from 147 health maintenance organisations with 20000 enrollees and higher, representing close to a $50 \%$ sample of all the organisations in that category. The first question asked in this survey was: "Is smoking cessation a covered service in your plan?" Sixty per cent said yes, and $40 \%$ no.

Another question asked was: "Do you have an in-house smoking cessation programme?" The response was: $46 \%$ yes, $54 \%$ no. There are two important aspects of these responses. First, if you were in a staff or group model health maintenance organisation, you were very likely to be covered and to have a programme available to you. Second, if you were an individual practice association or network member, you were much less likely to have that service available. And it is important to note that individual practice associations and network are the dominant forms of managed care and the ones that are growing the most rapidly in the United States.

Preferred providing organisations, which are somewhat in decline numerically, are another form of managed care, and there are data available on the percentage of these organisations offering health promotion and disease prevention services. That number is declining, and it was well under $25 \%$ in $1993 .{ }^{11}$ Also interesting to note is that the predominant model of in-house smoking cessation programmes - for those health maintenance organisations that offered it - was a group programme based either on the American Lung Association or on the American Cancer Society model.

Let us look briefly at prescription products for smoking cessation. At present, demand for nicotine products and transdermal patches is fairly stable, somewhere in the range of $\$ 50$ to $\$ 60$ million a year in sales for nicotine gum, and $\$ 150$ to $\$ 160$ million in sales for transdermal patches (SmithKline Beecham, unpublished data, March, 1995). While data are not available publicly, there appears to be a major problem with the perceived efficacy of prescription products. Anecdotal evidence suggests that many physicians and consumers have heard from some source or other that these products do not work. This perception may have a lot to do with smokers' expectations of what pharmacological treatments can do, but I believe it also has to do with a failure of communication or of encouraging the proper use of the products, or indeed of linking smokers looking for treatment with those everelusive "comprehensive behavioural smoking cessation programmes". The approved indication for the transdermal patch is as an effective adjunct when used with a comprehensive behavioural smoking cessation programme, ${ }^{12}$ and, as I indicated earlier, those are not widely available.

A major question is "If you are in managed care, can you get a patch?" The survey asked health maintenance organisations $(n=147)$ "Do you cover the transdermal nicotine patch?" The response was yes in $54 \%$, no in 
$45 \%$. There are some major restrictions that accompany coverage of the patch which I shall describe shortly.

In the case of over the counter (OTC) products, in June 1993, the FDA decided that none of the major smoking deterrent products, as the class was called, was shown to be effective and therefore ordered that they be removed from the market. The one that suffered the most was Cigarrest. I think this is a very instructive model, and I have often used it as an example. The 1988 sales of Cigarrest were approximately 1.75 million units. ${ }^{5}$ That equates with about $\$ 33-\$ 35$ million in sales. This was not an insignificant product in the minds of many consumers. What did it do better or different? The price was right, the package was right, and the promotion was right. It was aimed at a market segment that watched television and would respond to the opportunity to quit smoking by dialling a tollfree 800 number and charging $\$ 14.95$ on a credit card. How well did Cigarrest work? We may never know, but the fact is that the product itself was extremely popular to a significant segment of the smoking market. I think the most significant potential development in OTC products would be a shift from prescription to OTC status for nicotine gum (Nicorette $\left.{ }^{\circledR}\right)$ and for transdermal patches. Both of these switches are under consideration or in various stages of consideration by the manufacturers or by the FDA.

Next, consider the cost of cessation products and services. The average price for smoking cessation programmes is, I think, an important indicator of what consumers are willing to pay to quit smoking. The prescription costs, based on Washington prices without the benefit of a drug card discount, are $\$ 38.99$ for 96 pieces of $2 \mathrm{mg}$ nicotine gum, $\$ 54.99$ for 96 pieces of $4 \mathrm{mg}$ gum, and $\$ 54.59$ for 14 patches. The total cost of treatment, using these products at those prices, is going to depend on how long the treatment lasts. One of the major problems with gum and patches is that smokers apparently do not use them properly, do not use them long enough, or do not use enough of the product, and therefore treatment may be quite inexpensive because they never finish a complete course of treatment.

Another problem with prescription products is that reimbursement is limited. ${ }^{13}$ Excluding managed care, indemnity plans usually copy the same drug riders. My company made an effort to change our own drug rider just to see what would happen in our plan, and we were told that it would require us to relicense with the state of Maryland, which was excessively complicated, and besides it was a generous rider and these products are not effective; therefore, they are not covered.

We have calculated the sales weighted average price of non-prescription smoking cessation products, including group programmes and all the products available in 1993 (CHPG, unpublished data, 1994). The sales weighted average price was $\$ 76$. At its peak volume of about 1.75 million units, Cigarrest would have brought that sales weighted average price down to $\$ 41$. The calculation for commercially available self help programmes and those available through the voluntary health agencies was estimated to be $\$ 35$.

As indicated earlier, there are barriers to gaining access to products and services, particularly requirements on the prescription of transdermal nicotine and gum. Of those health maintenance organisations in the Ciba-Geigy survey that covered the patch, $67 \%$ had requirements of some kind, and $45 \%$ limited a prescription to once in a lifetime. If a smoker does not make it the first time around on the patch in those organisations, he does not get another chance.

There are other barriers to consider, including time to gain access to a programme: "How long do I have to wait before I can get help?" As I indicated earlier, in our informal survey of 10 cities in the United States we found that in four, the voluntary health agency offered no programme; two offered programmes requiring prompt action by the smoker; if the window of opportunity was missed, the smoker would have to wait another three months. In the remaining four, smokers would have to wait five to 10 weeks for the next group to start.

Knowledge and attitudes are also noteworthy barriers. In this case, researchers, clinicians, providers, and regulators seem to have a single set of attitudes about cessation products and services, often negative. I am not sure that we know what smokers' attitudes are about quitting smoking, particularly in terms of what types of assistance they would prefer to use. Yet I believe we are still dealing with a "one size fits all" mentality, which is driven by the concept of a comprehensive behavioural treatment programme which I have yet to see defined.

We also tend to deal in terms of treatment failure, and tell people in one way or another that "If you cannot quit on your own, you are a failure; if you cannot quit in six or eight weeks, you are a failure; and if you use nicotine replacement products for more than three months, you are a failure." Again, we have the problem of perceptions of efficacy. How effective does a programme have to be to be acceptable? What is acceptable efficacy? If you ask physicians and other health care practitioners what they consider to be an effective smoking cessation programme, they might not have an answer, but my guess is it would be significantly higher than the rates most of our programmes achieve.

Clearly, there are sociodemographic factors that affect the use of cessation support. How does the effectiveness of products and programmes vary among different minority groups, particularly different racial and ethnic groups, and are there significant differences in how the system treats these groups and how they respond to the system?

Finally, I want to consider factors that affect the system, to see what we can expect in the future. First is the switch of prescription cessation products to OTC availability. If this happens, it will make a major difference 
because it is likely to generate more demand for cessation through advertising and promotion of cessation itself. Second, I think we shall see efforts to define and develop new prescription products. However, they will face some of the same problems that nicotine replacement has in that the clinical response to them will be similar: "How do I use this properly, what kind of efficacy is acceptable, and how do I connect my patient with a comprehensive behavioural smoking cessation programme, or do I even bother?"

It is also important to consider how receptive the health care system is to new products. It is not likely to be receptive unless the price is right. Is there a continued need for behavioural support components? There is no question that we need them, but can we create better programmes that work quicker and easier, and are more accessible?

What will be the impact of demand generated by new products, and what about increased access? We have cessation guidelines under development by the Agency for Health Care Policy and Research (AHCPR), and I hope these are close to release. Will they be broad enough to encompass the new treatment concepts, and is there is a plan to institutionalise the guidelines? Will they fare better, for example, than the US Preventive Services Task Force recommendations for counselling by clinicians?

We also have disease management, an emerging concept launched by the pharmaceutical industry. Disease management offers interventions on a public health model, focused primarily on chronic diseases. There is some evidence that the smoking models of disease management are likely to prove effective. But there is a tension between the tendency of the health care system to standardise and "medicalise" those treatments that are foreign to it and the perceived need to offer more flexible treatment. How do we deal with this?

With managed care and health care reform, the basic question is: "When does the economic justification become irresistible?" Do the changing demographics and developments, such as Medicaid managed care, drive the economic issue to the point where managed care will be more forthcoming in offering cessation programmes and products?

What about consumer and payer demand? Are employers more likely to demand intensive interventions for their employees, and are they willing to pay additional premium dollars for coverage? I cite the lesson of health care reform. Many of my colleagues said that health care reform would institutionalise prevention. It is significant, however, that "smoking cessation classes and other health education classes" were the only optional benefit in the Clinton plan. ${ }^{14}$

These are my questions for the future. First, will the continuing costs of tobacco addiction and all substance abuse (despite declining prevalence) drive treatment investment? Second, is there a need and an opportunity to develop a tobacco addiction treatment policy that provides treatments as accessible and affordable as cigarettes? Third, can we both create and satisfy demand for treatment, tailored to individual smoker profiles and needs, with culturally appropriate treatment and marketing strategies? And finally, can we have a national strategy that balances prevention, policy, and treatment?

1 Fiore MC, Novotny TE, Pierce JP, Giovino GA, Hare quit smoking in the United States. Do cessation programs help? fAMA 1990; 263: 2760-5.

2 Derived from Giovino GA, Shelton DM, Schooley MW. Trends in cigarette smoking cessation in the United States. Tobacco Control 1993; 2 (suppl): S3-10, and Garvey AJ, Bliss RE, Hitchcock JL, Heinold JW. Predictors of smoking relapse among self-quitters: a report of from the Normative Aging Study. Addict Behav 1992; 17: 367-77. [Number of smokers who make an attempt to quit that lasts more than 24 hours, adjusted for the number that relapse within 24 hours.]

3 Borland R, Chapman S, Owen N, Hill D. Effects of workplace smoking bans on cigarette consumption. $A m \mathcal{F}$ Public Health 1990; 80: 178-80.

4 US Department of Health and Human Services. Reducing the health consequences of smoking: 25 years of progress. A report of the Surgeon General. Rockville, MD: US Department of Health and Human Services: 1989.

5 Corporate Health Policies Group, Inc. and Marketdata, Inc. Health promotion and disease prevention: Rx for the 1990 s? A complete analysis of market structure, emerging
issues, and trends. Valley Stream, NY and Bethesda, MD, 1994.

6 US Preventive Services Task Force. Guide to clinical preventive services: an assessment of the effectiveness of 169 interventions. Report of the US Preventive Services Task Force. Baltimore, MD: Williams \& Wilkins, 1989.

7 Gallup Organization. Smokers attitudes toward quitting. Princeton, NJ, September 1993.

8 US Centers for Disease Control and Prevention. Physician and other health-care professional counseling of smokers to quit - United States, 1991. MMWR 1993; 42: 854-7.

9 Group Health Association of America. HMO industry profile, 1993 edition. Washington, DC, 1993.

10 Corporate Health Policies Group. Market research study on smoking cessation and managed care. Bethesda, MD: CibaGeigy, 1993.

11 Marion Merrell Dow. Managed care digest. Kansas City, MO, 1993.

12 Medical Economics Data Production Company. Physicians' desk reference, 1995. Montvale, NJ, 1995.

13 Institute for the Study of Smoking Behavior and Policy. Smoking cessation-the organization, delivery, and financing of services, July 13-14, 1989. Cambridge, MA, 1990.

14 Health Security Act, Title I, Subtitle B, Sec 1127. Washington, DC, 1994. 